\title{
OBJECTIVE LIST THEORY OF WELL-BEING AS AN EXPLANATORY THEORY
}

\author{
BRUNO AISLÃ GONÇALVES DOS SANTOS ${ }^{1}$ \\ (Universidade Federal de Santa Catarina, Brasil)
}

\begin{abstract}
It is often argued that the so-called Objective List Theory (OLT) cannot support an explanatory view about what well-being is because the OLT cannot identify one single good-maker property that is responsible for unifying all the elements that compose the well-being. Then, the Objective List Theory can only be an enumerative view of well-being. In this paper, I aim to show that we may offer an explanatory view on well-being even without identifying a single good-maker property that is shared by all the elements that compose it. I hold that the OLT is still explanatory, because it is possible to identify each good-maker property in each element that is supposed to compose the list that is responsible for defining what well-being is. In addition, I hold that in order to have a full explanation of the concept of well-being we need to distinguish between two questions: 1) Why is something intrinsically good? and 2) How could the things that are intrinsically good benefit us? My conclusion is that we may conceive one explanatory and pluralistic list that has constitutive elements of well-being, and that a good explanation of well-being should include the distinction between the two aforementioned questions.
\end{abstract}

Key Words: Well-being. Objective List Theory. Explanatory Theory.

\section{Introduction}

In this paper, I intend to discuss the so-called Objective List Theory of well-being. I argue that one may conceive a pluralistic and explanatory list of general goods that involves both objective and subjective elements which compose human well-being. First of all, I will explain the differences between enumerative and explanatory theories about human wellbeing. Secondly, I will argue that in order to have a proper understanding of the Objective List Theory it is necessary to understand what 'goods' are on two levels, type and token. In the former, there are several general goods that can be directly good for anyone; also, its value is independent of us. In the latter, the occurrence of an event $X$ enhances the well-being of subject $S$ if and only if $X$ is an instance of a general good. Therefore, the Objective List comprises the 'general goods' that benefit us when we can access its instances. In the third step, I will delineate a method to select which 'general goods' must be part of the list. This method is divided into two parts: $1^{\text {a }}$ ) Following Rice (2013), we have to appeal to the socalled 'people's objectivist considered judgments about well-being' in order to reveal which goods may compose the list; $2^{\mathrm{a}}$ ) Once we have a 'good', we will analyse it to identify its good-maker property. To proceed in this analysis we should follow three conditions in order to know whether 'general goods' are, in fact, 'general goods': (i) a good cannot be just a 
means to another end; (ii) it must have a property that makes it valuable for itself; and (iii) it must be sufficient to increase well-being. Lastly, I will offer an objective list and argue in favour of the 'general goods' listed. Nevertheless, I argue that, although it is necessary to identify the good-maker property (in order to know what can benefit us directly), it is not a sufficient condition to explain how something that is good by itself can benefit us directly because we need to maintain well-being strongly tied to individuals. Then, my suggestion is that it is necessary to include the individual's pro attitude in the description of well-being. My conclusion is that it is possible to offer an Objective List that is explanatory and pluralistic.

\section{Enumerative and Explanatory Theories of Well-Being}

Well-being ${ }^{2}$ is commonly used to describe what is non-instrumentally good for an individual or what benefits a person directly. So, when we ask 'What is well-being?' we are interested in what kinds of things benefit a person directly. In philosophy there are three sorts of theories that try to identify what is non-instrumentally good:

(a) Mental State Theories;

(b) Desire Theories;

(c) Objective List Theories ${ }^{3}$;

My intention is to argue that one may conceive an Objective List Theory of well-being (OLT) that does not recognise that there is a common good-maker property shared by the different elements which compose the list, but that we are able to identify a range of elements to make our lives better. Thus, I will defend the OLT according to which all instances of a plurality of general goods benefit people directly. Indeed, is it possible for there to be an explanatory OLT? To answer this question it is relevant to explain what explanatory and enumerative theories of well-being are. ${ }^{4}$

Roger Crisp (2006) draws a distinction between enumerative and explanatory theories of well-being. Roughly, an enumerative theory of well-being offers just a range of elements that are supposed to be components of our well-being. The enumerative theory does not answer the question about what makes the components good for us, instead it only lists a set of elements that are the components of our well-being. On the other hand, the explanatory theory offers an answer to the question 'What is it about these things that makes them good for people?', in other words, explanatory theories identify one property that makes things good for an individual. This kind of theory can provide an explanation of the good-marker 
property. ${ }^{5}$ Crisp (2006) and Fletcher (2013) argue that it is impossible for an OLT to be explanatory because the OLT cannot identify a common good-maker property that is shared by all the components on the list. It would be impossible identify what kind of goods make the list and what kind do not. Then, it seems that an explanatory theory would be arbitrary. However, if the point is to 'identify the good-maker property' in order to be an explanatory theory, then the OLT still is explanatory if we can identify good-maker properties. Then, the challenge is to provide an OLT explanatory theory of well-being that does not identify an underlying feature shared by all goods on the list, but that can provide a justification for each general good.

In order to have an explanatory OLT that is pluralistic, ${ }^{6}$ we must answer three essential questions:

(a) What should compose the list?

(b) What are the good-maker properties according to the OLT?

(c) How do we decide what makes up the list? (Crisp, 2006)

Enumerative theories can offer answers to questions (a) and (c), but cannot offer an answer to question (b), because enumerative theories hold that there is no common property shared by the elements that makes good by itself; whereas explanatory theories can offer a proper answer to question (b) by identifying one or more properties that make things good for us.

Subjective theories of well-being, for example, can offer a proper answer to (b) by identifying, in general, only one element that composes the well-being and its good-maker. For example, the hedonistic view of well-being holds that 'pleasure' is the only good thing for its own sake. But then, we may ask, 'What makes 'pleasure' good for its own sake?' The common answer to this question holds that 'pleasantness' is the property that makes pleasure good for us. From the hedonistic point of view, the only thing that can benefit us directly is 'pleasure'. Notwithstanding, the hedonistic view has been developed and, as a result, it is available in a range of variations. For example, the simplest view of well-being ${ }^{7}$ was sustained by Bentham (1979). He argued that only 'pleasure' can benefit us directly, no matter what the source of pleasure is.

John Stuart Mill (2000) also held a hedonistic view, but for him the sources were important for the pleasure's 'quality'. In Mill's view, pleasure is the only thing that is good for its own sake, but some pleasures have more 'quality' than others since there are sources that produce a more valuable pleasure than others ${ }^{8}$. Contemporary philosophers, like Crisp 
(2006) and Feldman (2004), also hold hedonistic theories of well-being. In this respect, the important thing to notice here is that hedonistic theories are subjective theories of well-being. In other words, what makes our life better is positive mental states (In some theories the sources of positive mental states ${ }^{9,10}$ are important; in other theories they are not important at all.)

Nevertheless, the hedonistic view (at least, the simplest hedonistic view) has some problems: 1) Sometimes it seems that the sources of the mental states are not good, so it is hard to accept that someone could benefit from a mental state that comes from a source that does not seem to be good (e.g., someone who does cocaine all the time, or someone who takes pleasure in torturing people just for fun, etc.) and 2) There seem to be more things that can directly benefit us without producing positive mental states (for example, gaining knowledge even if we do not produce anything practical). The intuition behind this is that there seem to be some things are good for us independently of our mental states. I think that the explanation based only on internal aspects of well-being is not enough to give a proper explanation of the concept of well-being ${ }^{11}$ as it seems implausible to accept that all the things that can benefit a person may be reduced positive mental states. Also, it seems implausible to reject the intuition that there are things that are able to benefit us without generating mental states (any kind of mental states). I believe there are states of affairs that have value by themselves and that could benefit us non-instrumentally (for example, having an affective relationship). So it is plausible to consider the external aspects of well-being or, in other words, it is necessary to consider states of affairs that can benefit us directly without causing us to experience positive mental states.

The OLT, in turn, establishes that what is good for us non-instrumentally comprises a set of elements that have value independently of our mental states. Things are good even if we do not recognize their value or even if there are no mental states caused by them., once a particular individual could, for example, be in a bad epistemic position and may not be able to recognize that 'pleasure' is good non-instrumentally because 'having pleasure' is a sin for him. This kind of theory holds that what is important for making our lives better is not just mental states; instead, the important thing that make our lives better are a range of states of affairs that we can access. The difference between subjective theories and the OLT is that the latter holds that our well-being is not entirely dependent on our desires or mental states. To have well-being we have to access states of affairs that are good for their own sake. Consequently, what is good for us non-instrumentally depends on states of affairs too. The 
problem for the OLT is to offer a view of what makes these states of affairs good for us. The difficulty for the OLT proponents is to explain why the states of affairs are good for their own sake and how they can benefit us directly.

I think that in order to provide an explanatory OLT we have to keep separate two important aspects of what can benefit us non-instrumentally. The first aspect is about why certain states of affairs are good for their own sake. The second aspect is about how some states of affairs can benefit us directly without, necessarily, producing any positive mental states. If we keep these two aspects separate, it is possible to see that there are general goods that make our lives better without necessarily producing positive mental states or satisfying any desire. Furthermore, it would be possible to understand how 'goods' can benefit us in spite of not producing positive mental states when we have access to it instances. Nevertheless, a proper OLT cannot be the focused only on the external elements about wellbeing, because it is necessary to explain how the things benefit us. If we maintain the focus just in the external elements of well-being, then we cannot keep the well-being tied to the individual. In order to explain how the good things benefit directly a person, it is necessary, from my point of view, to explain why the things are good independently of the individual's mental states and how the good things have some impact on the individual's life.

\section{The General Goods and Instantiation}

According to Lauigier (2013), the OLT work on two levels: (i) the type level, and; (ii) the token level. In the type level, there are several general goods that are directly good for anyone and its value is independent of one's pro-attitudes towards them (Lauinger, 2013, p. 955). In the token level, the occurrences of an event $X$, benefit a person $S$ if and only if $X$ is an instance of a general good. Then, the list should be composed of a range of general goods that when instanced benefit us. If we accept that there is a set of general goods that makes the life better for anyone, then we have to accept that the value of these goods is not dependent on us. But, what kind of goods makes our lives better? Which are the properties that make these general goods valuable for themselves? by answering the first question we are able to answer the question (a) listed above.

In fact, there is a disagreement between the OLT proponents about elements that should make up the list but, generally, one List is composed of the following elements ${ }^{12}$ :

*Achievements 


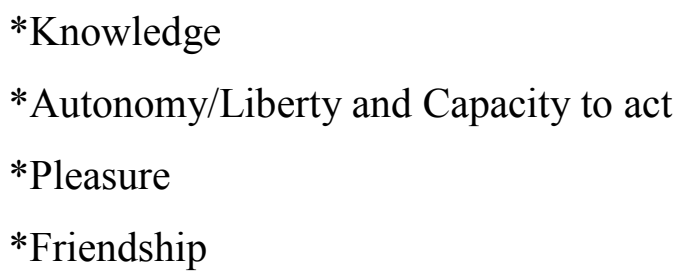

Besides these items, other elements could be included depending on the approach we are using. Some other elements that can go in the list are: second-orders goods (such as, having a life with a wide variety of goods), aesthetic appreciation, virtues, health, meaningfulness, and enjoyment ${ }^{13}$. Some items are more controversial than others, but in general, the intuition behind the list is that there are some things that are good for their own sake independently of the individual's mental states. The kinds of elements are on the type level, so they are able to be instantiated in different events or states of affairs. One way to explain what kind of thing is the 'general good' is, is to consider it as a set of events that share the same good-marker property. If an event can increase our well-being, it is an instance of a good-maker property; while 'good-maker property' is an objective feature that makes the events good for their own sake. For example, some instances of the general good 'achievement' could be 'writing a great novel', or 'being a good friend', or 'being a respectable citizen' etc.

Each particular state of affair instantiates the same good-maker property that is responsible for giving value to the event. The same rule is valid for the other general goods. If each general good has its own good-maker property, then all the states of affairs (or events) that instantiate could benefit us directly. For this reason, one may identify a range of instances on the token level that are good for their own sake. This view can explain why it is valuable to achieve a range of activities in our lives and explain why we think that these events are important for us. The distinction between the type and token levels aids us in understanding the plurality of views about how we must live. We can understand why different lives are valuable, since each life could have a different combination of the general goods' instances. On the other hand, to make an interpersonal comparison of well-being could be problematic. However, putting this problem off, I think that it is necessary to answer the basic questions first: how to identify the general goods and why they are good for us, in other words, what are the general goods and which are their good-maker properties?

\section{How do we decide what makes up the list and what should compose the list?}


One problem for proponents of the OLT is determining what kind of things the 'general goods' are and why they are good for their own sake. While the enumerative theories only determine the elements without identifying any good-maker properties, the explanatory theories offer a justification showing why each element is good for its own sake. On this topic, first of all, I will try to delimitate one method of choosing the elements that go on the list. Then I will explain which properties make such elements good for their own sake. In other words, I will try to identify the good-maker properties of the different elements that go on the list.

There are two ways, at least, to identify what kinds of things have to compose the objective list. One is to consider our intuition about what makes an individual's life better, the other one is to consider people's judgment about what makes life better (Rice, 2013). The difference between considering intuition and people's judgment is that in the first way (considering our intuition) we cannot offer public justification for each item that goes on the list. The second way supposes that people can offer justifications to include one element on the list. In general, the justification can be on account of objective or subjective aspects of the item. As Rice (2013) noticed, sometimes people can hold a subjective view about what good is for its own sake, in other words, the elements have value only if they cause positive mental states or satisfy desires. On the other hand, people can offer justification based upon the objective features of the items that are supposed to go on the list. It is possible to compose a list using people's objectivist judgments about well-being to determine which items to include. Rice (2013) offers one view that uses this kind of judgment.

The first step of the method I am following here in order to select what kinds of elements have to compose the list is the appeal to people's objectivist considered judgments about well-being, like Rice does (2013). People's considered judgments are used by different philosophers to establish a range of principles in a specific theory ${ }^{14}$. However what Rice offers is another view about people's considered judgments. He suggests that we have to look for people's objectivist judgments about well-being.

These are people's objectivist judgments about well-being. Many people judge that certain states of affairs contribute to well-being on account of their objective features, and not because people hold positive reactive attitudestoward them. Loving relationships, for example, are judged to be good for people because they involve reciprocal love. Similarly, meaningful knowledge is judged to be good for people because it involves appropriately justified beliefs about meaningful truths. (RICE, 2013, p. 202). 
When we ask people what kinds of things are supposed to benefit an individual directly, they can offer a judgment, not on account of mental states or positive attitudes, but due to the objective features that make each state of affairs objectively good for a person. The problem is that people can value these states of affairs for reasons beyond well-being, as Rice (2013) argues. However, when we are asking about well-being, people can offer justifications for something to be 'good' without an appeal to justification based upon satisfaction of desires or production of positive mental states. And Rice's view is different from the 'impartial judge' strategy because Rice does not hold that people must be completely informed about the state of the world to make statements about what kinds of things contribute to well-being. The way I see it, Rice holds that people's objectivist judgments are necessary to explain why a set of states of affairs benefits people independently from their subjective attitudes. Nevertheless, I think that it is not sufficient to only identify the good-maker property to explain well-being. It is necessary to explain not just why things are good for their own sake, but also how a set of states of affairs benefits us. It is necessary to explain how the elements have an impact on the individuals' lives ${ }^{15}$.

For my turn, I suggest that we have to use people's objectivist judgments about wellbeing as the first part of the method to select what can benefit us non-instrumentally. I am suggesting this for two main reasons: 1) because I think that people's objectivist judgments sometimes could be partial or wrong for some reason, ${ }^{16}$ even if people judge the objective properties that make something good for its own sake. However, we can still use people's objectivist judgments, but these judgments have to follow some conditions so as to avoid and correct possible mistakes. 2) Even if people are able to make judgements about objective properties that make things good for its own sake, mere agreement among people cannot decide on its own 'what is or is not good' non-instrumentally. We need to delineate some conditions that the general goods must satisfy to be a general good. We can consider that people's judgements are just the first step in a clearer analysis of the elements that have to compose our list. The second step is to check whether each element people's objectivist judgements point to is a general good in order to identify if what was elected has a goodmaker property or not (if in fact the thing has a good-maker property). I think that the second step is important to avoid something that is not good for its own sake going on the list. Then, the second step in the method is responsible for trying to correct or avoid any possible mistake that people could make their judgments. To proceed with this analysis of what is good for its own sake, I think, that it is necessary to follow three conditions in order to know 
if the 'general good' is, in fact, a 'general good': (i) the 'good' cannot be only a means to another end; (ii) it must have a property that makes it valuable for itself; and (iii) it must be sufficient to increase well-being. The three conditions listed above are responsible for avoiding mistakes in the scrutiny of the state of affairs that have to compose the list $^{17}$.

The first condition establishes that we are looking for non-instrumental goods. It is necessary to give some explanation about this. When we talk about 'means' and 'ends' we are talking about one specific relation where something has the instrumental value to achieve another thing (in fact, sometimes there is more than one means to achieve the same end). For example, in order to cure your flu, you need to get vitamin D. Then, 'getting vitamin D' is one means to cure the flu and 'curing the flu' is one means to another thing, let's say, 'staying healthy' and so on. However, there are some things that are good even if they are not means to another thing. For example, 'gaining knowledge' seems good for its own sake even if we do not use this knowledge to do something practical (for instance, to cure a disease or build bridges, etc.) and some subjects (e.g. philosophy) do not have practical application, but it is still valuable to know them. Then we are looking for things that are valuable in themselves, even if they could have (or not) a practical application. ${ }^{18}$ That is what I have in mind when I say that: 'the 'good' cannot be only a means to another end'. The second condition is about identifying the good-maker property, in other words, what feature is responsible for making the general good good for its own sake. In order to identify the good-maker property, we need reasoning about the characteristic that the 'good' has. The third condition establishes that the good has to be sufficient for an individual to increase their well-being. The third condition is more controversial because it is not clear what we mean by the concept of 'sufficient'.

As 'well-being' can be measured in degrees (somebody could have more or less 'wellbeing'), the concept of 'sufficiency' here is not clear, because one individual can live without one element set out on the list and, even so, could have some degree of well-being. What I meant by 'sufficient to increase well-being' is when you access the instantiation of a general good, your well-being increases. Thus, the general good is sufficient for well-being when we access any instances of it and our well-being increases. Following people's objectivist judgments about well-being and the three conditions that are necessary to analyse well what should compose the list, I think that one may recognize, at least, the following general goods:

*Autonomy

* Affective relationships

* Meaningful achievements 
* Knowledge

* Pleasure

* Self-Respect

It is possible that people's objectivist judgements support all these general goods and others, but I do not intend to present a complete list. Offering a complete list, a list that covers all aspects of well-being, is not possible here because offering a complete list depends on how much we know about human beings' nature and about the nature of the world. However, we have one method of deciding which elements should compose the list, and we can identify the different elements that go on the list. But for now, I am going to work with these six elements. I will then try to identify the good-maker properties, in order to explain why each of these elements is good for its own sake. In a second step, I will go on to discuss how they benefit us.

\section{Which are the good-makers according to the OLT?}

Like I said above, I assume that there is not just one good-maker property that makes all the general goods valuable. On the contrary, I have assumed that each of them has its own good-maker property. Hence, I will explore each general good trying to identify the goodmaker properties.

\section{Autonomy}

First, I will discuss why autonomy is good for its own sake. The discussion about 'autonomy' is recurrent in philosophy. Classical philosophers like Immanuel Kant (2009) and John Stuart Mill (2000) gave autonomy an important place among the ethical theories. However, their understanding of what autonomy is and why autonomy is valuable is different. Kant holds, roughly, that being autonomous is the capacity to give yourself a rule and follow this rule; whereas, J. S. Mill holds, in brief, that being autonomous is the capacity for selfdetermination without external influences. ${ }^{19}$

What those two descriptions have in common is that 'autonomy' is related to the idea of self-government. An individual is 'autonomous' when he is able to make a rational and unconstrained decision. Thus, we say that someone is autonomous from an objective point of view when he is capable of making rational decisions and executing activities in an 
unconstrained way. What, then, is the good-maker property of autonomy? I think that the good-maker property is self-government. So, 'autonomy' is good for its own sake, because it involves 'self-governance'. One who is able to self-govern is better off than one who cannot make a genuine choice. For example, some cultures disseminate that some of the people who compose the society may not be autonomous. An example is a sexist society which considers women to be in an inferior position in relation to men. This type of society in which women cannot play important roles does not allow them to make autonomous decisions. Usually, the men are responsible for making the important decisions about the women's lives. In this way, a woman is not allowed to self-govern her life.

When we cannot make important decisions about our own lives, it is hard to see how we can enjoy a genuine life full of well-being. It seems central in a good life to choose one way to live, in other words, it is important to be able to choose different activities, relationships, roles to play in society, etc. in order to have a particular life plan. If you cannot choose the important things in your life plan, probably, you will not be able to live a genuine life full of well-being. Then, from an objective point of view, in general, people that cannot self-govern their lives are worse off than people who can self-govern their lives. It is important to note that some people are unable to be autonomous, for instance, children, people with severe disabilities or people who are temporarily restrained (people in a coma, e.g.). However in all these cases the people have autonomy in a dispositional way. In other words, if these people were in a different position (the children grew up, the disabilities were cured, the coma state surcease $\mathrm{d}^{20}$ ), it would be possible for them to make autonomous decisions. In short, autonomy is valuable for its own sake because it has the good-maker property of self-government, and 'being autonomous' can benefit us because we can make rational and unconstrained decisions about our life plan.

\section{Affective relationships}

Nowadays, an individual can have a range of interpersonal relationships, for example, at work, in society, in their family etc., but some of these relationships are more important than others in human life. Sometimes an interpersonal relationship at work is not relevant to an individual's well-being and the same occurs in relationships within the family or society. In spite of that, some relationships are very important for us and have value for their own sake; we can call these kinds of relationships 'affective relationships'. 
As Rice (2013) proposes, affective relationships are valuable because they involve reciprocal love. Affective relationships can benefit us once reciprocity occurs, so the goodmaker property of affective relationships is reciprocal love. Having this kind of interpersonal relationship can benefit us independently by causing in us, for example, a specific mental state of pleasure. In fact, sometimes maintaining a relationship can be very hard and painful since relationships demand attention, commitment, etc., but having a relationship that involves reciprocal love can benefit us directly.

Obviously, these affective relationships can involve pleasure because we can enjoy the company of another person, but what makes an affective relationship good for us is not the pleasantness or the enjoyment, but instead the reciprocal feeling of love. It seems then that the good-maker property of affective relationships is the reciprocal love. Like I said above, some relationships do not have this feature; therefore, they do not have non-instrumental value. For example, an individual who does not love their parents cannot benefit from the parental relationship because the relationship does not have objective value; it seems that we cannot call this relationship an 'affective relationship'. Apparently, having blood ties is not a necessary condition for a relationship to be able to benefit us. To make sense, an affective relationship needs a commitment from both sides (the commitment that persons love each other) and this commitment does not come through blood ties or social arrangements (like arranged marriage), an affective relationship comes through spontaneous and implicit commitment. On the token level there is a range of affective relationships that can benefit us directly, for example, fraternal, parental, loving relationships ${ }^{21}$ and so on, and, in each of them, it is necessary to have reciprocal love.

\section{Meaningful achievements}

Many proponents of the OLT suggest that 'achievements' or 'accomplishments' have to feature on a list that describes what benefits us non-instrumentally, but 'achieve something' does not always seem good for its own sake. For example, if a person's aim of life is to write all the numbers from zero to one trillion and spend their whole life writing the numbers, it seems that they do not increase their well-being when they finish the activity, because it seems that the achievement of 'writing all the numbers from zero to one trillion' meaningless. If, in fact, this kind of achievement has no meaning, it seems that it has no value. On the other hand, there are some achievements that seem full of meaning and that could increase our well- 
being, e.g., 'being a good parent', 'writing a great novel', 'being a concerned citizen towards humanity' and so on. The difference between the first case and the second one is not only that the first is based on the senseless desire of an individual; the difference remains in the achievements themselves. Some achievements are valuable in themselves, while others are not valuable in any way. An achievement's value depends on the meaning of the achievement, so if an achievement is meaningless, it will have no value. Now, it is necessary to try to elucidate the notion of 'meaningful achievements'.

To 'achieve' something is to fulfil a goal, but 'the goal' must be worth seeking and reaching for, so an achievement has a meaning when it reaches an objective worth being pursued. However, this answer is not suitable because we do not know what property makes the goal worth pursuing and reaching. We could think that the goals which have meaning are those that a rational individual would seek to include and achieve in their life plan. It seems that a rational person would not include senseless achievements in their life plan as it is irrational to pursue an objective that does not result in something worthwhile. Then we can think that 'meaningful achievements' are those it is rational to seek and accomplish. In my first example, it seems that it is irrational to write out all the numbers from zero to one trillion because seems pointless. In short, 'meaningful achievements' are those that a rational being would choose for their rational life plan. Assuming that it is plausible, one question remains: what is the good-maker property that makes 'meaningful achievements' good for their own sake? In my view, the good-maker property of meaningful achievements is fulfilling our rational life plans since rational life plans include the pursuit of worthwhile objectives. Then, meaningful achievements increase our well-being because we can fulfil our worthwhile objectives in our own lives. The value of achievements does not depend on just our desires or mental states because, like I said in my first example, some achievements have no value even if we desire them. It is necessary that an achievement has meaning and "having meaning" means 'being rational to reach worthwhile objectives'.

\section{Knowledge}

Acquiring knowledge could be an important aspect of well-being. Knowing the relevant aspects of the world and our own nature seems relevant to well-being. Rice argues that people's objectivist judgments would recognize 'knowledge' as an element of well-being 'because it involves appropriately justified beliefs about meaningful truths' (Rice, 2013, p. 
202). But 'knowledge' does not have to be 'appropriately justified beliefs about meaningful truths', it has to be just about 'truths'. The important thing about knowledge is appropriately justified beliefs about truths, since when we gain knowledge about simple things this is also important for our well-being. To know something does not benefit us just when we know about physics, or chemistry, or cosmology and so on. Knowing who you are, what kind of things your family expects from you, how your community organizes itself, etc. is also important for increasing your well-being.

Acquiring knowledge is not good for its own sake just because we desire to know the relevant aspects of the world or because we will gain pleasure from more 'quality'. Even if people do not seek or wish to know, 'knowledge' seems to make their lives better. Not only science but also religion and philosophy are examples of seeking the truth for itself and considered as good in itself. It seems that knowledge is an end in itself because it involves the truth, without needing to add anything else. Even though knowledge does not bring any practical consequences (such as inventing something new or producing a cure for a disease), it is good, because it shows us the truth and gives us reasons to explain the reality in which we live. Objectively, knowledge of the relevant aspects of the world is valuable in itself, and its essential characteristic involves truth and justification of our beliefs.

\section{Pleasure}

Currently 'pleasure' is understood in a subjective way because its value depends on just the mental states of an individual. However, we can understand 'pleasure' as having value because it has an essential feature, namely, pleasantness. Thus, the good-maker property of pleasure is 'pleasantness'. But it seems that some 'pleasures' are not good non-instrumentally for us. As I argued above, it seems that some pleasures do not have value (for example, doing cocaine all the time). All things considered, the pleasure arising from the continued use of cocaine, for example, seems to be intrinsically bad for us because such pleasure will bring about serious losses for us in the long term. Then, it is plausible to argue that pleasure has value, but not all pleasures have such value because all things considered some pleasures are bad for us in the long term. In this way, pleasure's value does not depend just on our mental states but also on its sources. As Mill accepts, some sources will give us pleasure with different qualities, and some qualities could be bad. Such sources could be identified by considering all the things that will not bring bad consequences for one's life in the long term. 
Pleasure is non-instrumentally good for us because its pleasantness comes from certain sources. Then, pleasure's value does not just depend on pleasantness, but also on certain sources $^{22}$.

\section{Self-Respect}

It seems to be more difficult to identify an essential feature of the last item on the list that I am suggesting here. This is because 'self-respect' can acquire various meanings. Commonly, we think that self-respect involves not being subjected to ridicule, or having a sense of self-confidence, or even having a set of basic rights guaranteed (as was suggested by Rawls (2008)). However, we intuitively associate self-respect with the ability to feel selfworth from what makes us human beings. This involves various things like acting so as not to expose ourselves to ridicule, to the arbitrary will of others, to degrading activities (like being a slave, for example) or to situations that degrade us into mere instruments. My suggestion is that self-respect is good for us because it is related to the act of maintaining our own dignity. Having dignity means seeing yourself as a person who deserves respect (from others and from yourself).

I believe the general goods described above are worthwhile goals in themselves and their value is irreducible to any other characteristic than their own essential feature, in other words, the value does not depend on individual attitudes. And, I think that people's considered objectivist judgments could support all of them as things that are valuable for their own sake. But how must well-being be understood? I will defend that how something benefits us depends on a kind of individual attitude that I will call 'pro-attitude'.

\section{How can the general goods benefit us?}

To understand the separation between why something is good and how something benefits us, we need to keep in mind that there is one difference between (i) things that advance our well-being and; (ii) things that are good. Philosophers argue that the difference is that (i) does not necessarily imply that what advances our well-being is good for its own sake, in other words, what advances your well-being only depends on an individual's attitude (or mental state, or desire). On the other hand, (ii) implies having something good for its own 
sake that is independent of an individual's attitude, or mental state, or desire. For example, it could seem good for you, but not be good at all, to take advantage of the suffering of others.

Despite the distinction being controversial, ${ }^{23} \mathrm{I}$ think that in order to have one proper description of well-being we need to consider these two things as different but complementary. To know (i) we need to know what (ii) is. The reason for thinking in this way is that if you consider just (i) as relevant in explaining what well-being is, you will find some counter-intuitive results, like the example above. It seems implausible to accept that you can benefit from a bad source (something that is bad in itself). But if you consider just (ii) to explain what makes your life better, you cannot explain how things that are good for their own sake advance our well-being, as the things that make your life better must have some impact on you, and for something to have some impact upon you, you must notice it. When we talk about well-being we have to consider things that are good for its own sake and such things are able to advance our well-being. However, to only identify what is good for its own sake does not explain how events can benefit us, so we need to add one more element, namely, 'individual attitude'. Then we can explain why things are good for their own sake and how these things advance our well-being. Thus, in order to increase our well-being, we must have an attitude in relation to things that are good for their own sake. It is possible to express this idea as follows:

$\mathrm{OLT}_{\text {attitudinal: }}$ State of affair $S$ benefits non-instrumentally an individual $I$, iff $S$ instantiates the essential feature of at least one of the general goods and $I$ has pro- attitude to access $S$ in appropriate circumstances.

Therefore there are two conditions to establish how some states of affairs directly benefit us: (1) the states of affair must instantiate one (or more) essential features of one general good (at least); and (2) the individual has to have a 'pro-attitude' to access these states of affair in appropriate circumstances. It is necessary to offer some explanation of what 'having a 'proattitude" and 'appropriate circumstances' are to make the second condition clear.

To have a 'pro-attitude' towards a state of affairs that is an instance of the general good is have a proactive attitude to engage in the search or include in your life plan fulfilment or access to the instances of general goods. Then, when you have a pro attitude towards an instance of the general good you recognize it and act in the world to fulfil it or to access the instance as good for your life. 
The 'appropriate circumstance' implies that the individual is informed about the relevant aspects of the states of affairs that can benefit them and that they are rational when they have a pro attitude towards an instance of the general good. If we are not informed about the relevant aspects of the states of affairs it is not possible to know when a state of affairs benefits us, because the information is relevant to the state of affair for it to cause some impact on us. But, why do we need to accept the second condition if the first one determines that something just benefits us if it instantiates the essential feature of the general goods? Why is it necessary to have a 'pro-attitude' in an appropriate circumstance? I think that the second condition is important, because if we are not actively seeking a state of affairs, even if it occurs, it may not have any impact on our life, simply because we do not recognize its value. The second condition is responsible for keeping well-being strongly tied to an individual. The important thing to note is that when we have an attitude satisfied we have a chance in our lives. However, the 'pro-attitudes' that are relevant to advance well-being are those which have as a reference the states of affairs that are instantiations of the general goods that are good for their own sake. Therefore, if we consider (1), then we have an evaluative standard for what the instances of the general goods are that is independent of our attitudes. On the other hand, if we consider (2) we explain how the instantiation of the general good can benefit us.

Rice (2013), in turn, does not stipulate the second condition and thinks that it is enough to explain well-being just using the first condition. Rice (2013, p.200) says: 'OL explan: States of affairs non-instrumentally benefit people because, and only because, they instantiate the essential features of at least one of a plurality of basic objective goods'. But, even if we have one instantiation of a general good, I cannot see how an individual could benefit directly without engaging in the search for and realization of these states of affairs. For example, 'writing a novel' benefits me, in accordance with Rice, but if I am not interested in writing a novel, I cannot benefit from it. To have an instantiation of a general good is necessary, but not sufficient to explain how something can benefit us. How I see it, it is necessary for the individual to have an attitude regarding instances of general goods. If you do not have an attitude for any instantiation it is not possible to benefit directly from the general goods, so it is not possible to increase your well-being. Thus, in order to keep well-being strong-tied to the individual it is relevant that the individuals engage in the search for and realization of these states of affairs. 


\section{Conclusion}

In this work, I tried to present an explanatory OLT. I outlined a method to support the allegation that some general goods have to go on the list to help us describe what well-being is. I defended that a good explanation of well-being should keep two aspects of well-being separate: 1) why some kinds of things are good for their own sake and; 2) how these things can benefit us directly. Then I offered a list with, at least, six general goods, and I tried to identify the good-maker properties of each one, which are: autonomy, affective relationships, meaningful achievements, knowledge, pleasure, self-respect. Since I stipulated each general good, I held that for a person to benefit directly from each instance of the general good, an instantiation of the general good and an individual pro-attitude are necessary. 


\section{Notes:}

${ }^{1}$ Doutorando no Programa de Pós-Graduação em Filosofia da Universidade Federal de Santa Catarina (UFSC), Florianopólis, S. C., Brasil. E-mail: brunoaisla@hotmail.com

${ }^{2}$ I will take the term 'well-being' to be synonymous with 'welfare' and 'personal good'.

${ }^{3}$ This taxonomy was made by Derek Parfit, (1984, pp. 493-502).

${ }^{4}$ Much below is related to the ideas of Andrew Moore (2000) and Christopher Rice (2013). The first suggests that the general basic goods can be their own good-makers while the second argues that as a method to identify the general basic goods through their essential features we should use the 'person's objectivist considered judgments' about what makes up well-being. However, Moore just suggests that the general goods can be their own good-makers, but does not develop any accurate description of this idea. In contrast, Rice did not discuss in depth in his article what makes each general basic good a general basic good (i.e., what the essential properties of each of them are). Rice advocates a method to identify what these general goods are consisting of appeals to people's objectivistic considered judgments about well-being. For my part, following the Rice method, I am trying to identify the essential features that make each general basic good valuable and, I believe, that people's considered judgments about well-being would point in the direction I am taking. Nevertheless, I diverge from Rice on the point that I believe that identification of the essential feature of the general goods is just one part of the explanation of well-being.

${ }^{5}$ I will use the terms 'good-maker property' and 'essential features of the general goods' interchangeably to refer to the property that makes something good for its own sake.

${ }^{6} \mathrm{OLT}$ is 'pluralistic' because the list involves objective and subjective elements.

${ }^{7}$ For the sake of argument, I will consider that 'well-being' and 'happiness' have the same meaning, but one may consider that the notion of 'well-being' includes more elements than the notion of 'happiness'.

${ }^{8}$ To see more about Mill's theory of value, see: DONNER, W. Mill's Theory of Value. In: WEST, H. (org) The Blackwell Guide to Mill's Utilitarianism. Oxford: Blackwell Publishing, 2006; DONNER, W. \& FURMERTON, R. John Stuart Mill. Lisboa: Edições 70, 2011; CRISP, R. Routledge Philosophy Guidebook to Mill on Utilitarianism. Londres: Routledge, 2006, pp. 19-62;

${ }^{9}$ For example, as we saw, for Bentham what causes the positive mental state called 'pleasure' is completely irrelevant for well-being, so well-being is only the presence of such mental states. Moreover, Mill considers that the sources of mental states are important because the cause may interfere with the quality of the positive mental states. Others may argue that states of affairs that are external to us are relevant. For instance, Adams holds that certain states of affairs have excellence and they are relevant for well-being (excellence is an objective and not a relational value that cannot be reduced to mental states), but only benefit us if we enjoy them, thus they are part of the individual experience and benefit directly the individual. In short, according to Adams' view, only the states of affairs that have excellence could benefit us directly if we enjoyed them. A defence of the last position can be found in ADAMS, R. Finite and Infinite Goods. New York: Oxford University Press, 1999, p. 99ss.

${ }^{10} \mathrm{By}$ 'positive mental states', I am referring to mental states like 'pleasure' and 'enjoyment'.

${ }^{11}$ To see more critiques of the internal view of well-being, see: SARCH. A. Internalism about a person's good: don't believe it. Philos Stud, 2011, pp. 161-184.

${ }^{12}$ Adapted from Mulgan, 2012, p. 42.

${ }^{13}$ To see more on these elements, see Finns, 1980; Parfit, 1984; Griffin, 1986; Wolf, 1997; Geter, 1998; Mill, 2000; Valerius, 2003; Ferkany, 2012; Fletcher, 2013; Rice, 2013, Hooker, 2015.

${ }^{14}$ For example, Rawls (2008) uses the so-called 'equilibrium reflexive' in order to choose principles of justice. 
${ }^{15}$ I think that it is necessary to make a distinction between two important questions of well-being: (a) why some kinds of things are good for their own sake and; (b) how these good things can benefit us. I think that the Rice's view can help us answer (a), but I think that his position fails to answer (b). I discuss this more in the below.

${ }^{16}$ Even if people are considering the objective features to elect what kind of states of affairs are good for their own sake it is possible that some mistakes arise. If people are not in a good epistemic position to make a judgment, it is possible that judgments could be wrong. In fact, in the real world, there are people who are not in a good epistemic position to judge what kinds of states of affairs are good for their own sake. It is for this reason that I think it is necessary to take a second step in the method to correct the possible selection mistakes concerning what go on the list.

${ }^{17}$ In fact, I think that people have to consider these three conditions when they are making judgments. These conditions can help us avoid mistakes and provide better justifications to elect a good as a general good. As I said, although people are reasoning about objective features, it is possible some mistakes occur. Following the three conditions can help us avoid mistakes or correct them.

${ }^{18}$ Aristotle (2009) separated the 'goods' into three categories: 1) Things are good because they are necessary to achieve other things; 2) Things that are good for own sake, but could be means to another end and; 3 ) Things that are good for their own sake and cannot be means to another end. For example, some 'achievements' (e.g. 'become a good doctor') can be meant for another purpose (e.g. 'cure people'), but could be good for their own sake, while other 'achievements'(e.g. 'combat poverty') could not be meant for another thing (maybe, 'combat poverty' could be good for its own sake only because we are trying to avoid unnecessary suffering). Although some instances of the general good seem like (2), the general good itself has to be of type (3), because all the instances have the same good-maker property.

${ }^{19}$ Mill did not use the concept of 'autonomy', instead, he resorted to the concept of 'individuality'. However, we may interpret the idea of 'individuality' as a notion of 'autonomy', because it seems that Mill has in mind something close enough the conception of 'autonomy'.

${ }^{20}$ Obviously, some persons are not able to self-govern for some reason (having an incurable disease, for example). In such cases, we may say that these persons would have less well-being than others who are capable of self-governing their lives.

${ }^{21}$ An affective relationship could be not solely between human beings. It is possible to have an affective relationship between humans and animals. Of course, we need to suppose that animals are able to love humans. I believe that this assumption is plausible and important in explaining why we can benefit from relationships with animals.

${ }^{22}$ I think that the relation between sources of pleasure and mental states of pleasure is a problem we cannot solve in this paper, but it is an important problem to research.

${ }^{23}$ For a discussion on this distinction, see: Hurka, 1987 and Bond, 1988. 


\section{Referencies :}

ARISTÓTELES. Ética a Nicômaco. São Paulo: Editora Atlas, 2009.

ADAMS, R.M. Finite and Infinite Goods. Oxford: Oxford University Press, 1999.

BENTHAM, J. Princípios da moral e da legislação. In: Os Pensadores. São Paulo: Abril Cultura, 1979.

BOND, E. J. 'Good' and 'Good for': A Replay to Hurka. Mind, Vol. 97, pp. 279-280, 1988.

CRISP, R. Reasons and the Good, Oxford: Clarendon Press, 2006.

Routledge Philosophy Guidebook to Mill on Utilitarianism. Londres: Routledge, 2006.

DONNER, W. \& FURMERTON, R. John Stuart Mill. Lisboa: Edições 70, 2011

DONNER, W. Mill's Theory of Value. In:WEST, H. (org) The Blackwell Guide to Mill's Utilitarianism. Oxford: Blackwell Publishing, 2006.

FLETCHER, G. A Fresh Start for the Objective-List Theory of Well-Being. Utilitas, Vol.25, pp. 206-220.

FELDMAN, F. Pleasure and the Good Life, Oxford: Claredon Press, 2004.

FERKANY, M. The Objectivity of WellBeing. Pacific Philosophical Quarterly 93, p.472492, 2012.

FINNS, J. Natural Law and Natural Rights. Oxford: Clarendon Press, 1980.

GETER, B. Morality: Its Nature and Justification. Oxford: Oxford University Press, 1998.

GRIFFIN, J. On Human Rights. Oxford: Oxford, 2008.

Well-Being. Its Meaning, Measurement, and Moral Importance. Oxford: Oxford University Press, 1986.

KANT, I. Fundamentação da Metafísica dos Costumes. Lisboa: Edições 70, 2009.

HURKA, T. 'Good' and 'Good for'. Mind, pp.71-73, 1987.

LAUINGER, W. A. The Strong-Tie Requirement and Objetive-List Theories of Well-Being. Ethical Theory and Moral Pratice, pp. 953-968.

MILL, J.S. A Liberdade/Utilitarismo. São Paulo: Martins Fontes, 2000. 
MOORE, A. Objective Goods. In: CRISP, R. \& HOOKER, B. (orgs) Well-Being and Morality. Essays in Honour of James Griffin. Oxford: Clarendon Press, 2000.

MULGAN, T. Utilitarismo. São Paulo: Editora Vozes, 2012.

NOZICK. R. Anarquia, Estado e Utopia. Lisboa: Edições 70, 2010.

PARFIT, D. Reason and Person. Oxford: Clarendon Press, 1984.

RAWLS, J. Uma Teoria da Justiça. São Paulo: Martins Fontes, 2008.

RICE, C. Defending the Objective List of Well-Being. Ratio, XXVI, 2013, pp.196-211.

SARCH. A. Internalism about a person's good: don't believe it. Philos Stud, 2011, pp. 161184.

Multi-Component Theories of Well-Being and Their Struture. Pacific Philosophical Quarterly 93, pp. 439-471, 2012.

VALERIUS, J. Autonomy, Subject-relativity, and Subjective andObjective Theories of Wellbeing in Bioethics. Theoretical Medicine 24: 363-379, 2003.

WOLF, S. Happiness and Meaning: Two Aspects of the Good Life. In: Social Philosophy \& Policy, 14 (1997), pp. 207-225. 